\title{
Research Paper: Intrinsic Factors of Home Fall Among Older Adults in Qazvin City, Iran, 2018
}

\author{
Amaneh Bagheri Roochi' (iD, Fatemeh Mohammadi² (D), Hossein Khorani' ${ }^{1}$ (D), Seyedeh Ameneh Motalebi ${ }^{2^{*}}$ (iD)
}

1. Student Research Committee, School of Nursing and Midwifery, Qazvin University of Medical Sciences, Qazvin, Iran.

2. Social Determinants of Health Research Center, Research Institute for Prevention of Non-communicable Diseases, Qazvin University of Medical Sciences, Qazvin, Iran.

\begin{tabular}{|c|c|}
\hline $\begin{array}{l}\text { Use your device to scan } \\
\text { and read the article online }\end{array}$ & ditation Bagheri Roochi A, Mohammadi F, Khorani H, Motalebi SA. Intrinsic Factors of Home Fall Among Older Adults \\
\hline 口fris & $\begin{array}{l}\text { in Qazvin City, Iran, 2018. Iranian Rehabilitation Journal. 2021; 19(Special Issue):29-36. http://dx.doi.org/10.32598/irj.20. } \\
\text { SpecialIssue.825.2 }\end{array}$ \\
\hline 口b+itis & dol http://dx.doi.org/10.32598/irj.20.SpecialIssue.825.2 \\
\hline
\end{tabular}

Article info:

Received: 29 May 2021

Accepted: 08 Nov 2021

Available Online: 01 Jan 2022

Keywords:

Fall, Aging, Imbalance, Physical activity

\section{A B S T RACT}

Objectives: This study was conducted to determine the prevalence and predictors of home fall among elderly people living in Qazvin City, Iran, 2018.

Methods: This cross-sectional study was performed on 300 elderly people aged 60 years or higher who were selected by cluster sampling technique. Data were collected by demographic and chronic diseases checklist, checklist of the characteristics of fall in the last year, Abbreviated Mental Test (AMT), self-reported health scale, and Timed Up and Go (TUG) test. The logistic regression model was conducted to determine predictors of home falls.

Results: The mean age of the 300 older people who participated in the study was $70.11 \pm 8.90$ years. Approximately, one-third of them $(n=100,33.3 \%)$ reported at least one fall during the last year. The results of the logistic regression revealed that the number of medicines used $(\mathrm{OR}=5.31, \mathrm{CI}=1.44-19.49)$, history of the physical disease $(\mathrm{OR}=1.31, \mathrm{CI}=1.01-1.70)$, age $(\mathrm{OR}=1.09, \mathrm{CI}=1.03-1.15)$, balance control $(\mathrm{OR}=1.04, \mathrm{CI}=0.07-1.01)$, and physical activity $(\mathrm{OR}=0.72, \mathrm{CI}=0.57-0.92)$ were internal predictors of the fall among older adults.

Discussion: The findings of our study disclosed that the incidence of falls is rather high among older people. The frequency of falls increased by advancing age, increase the number of physical illnesses and medicines used, poor balance, and a reduction in physical activity.

\section{* Corresponding Author:}




\section{Highlights}

- About one-third of the older people experienced at least one fall during last year.

- The results indicated that older participants were more likely to experience falls than their younger counterparts.

- The results also showed that increasing the number of physical illnesses and medications used, the time to complete the TUG test, and decreasing the rate of physical activity significantly increased the risk of falls among older people.

\section{Plain Language Summary}

Falls are one of the most frequent and serious problems facing the elderly. The aim of this study was to investigate the prevalence of falls and correlated factors amongst 300 older people residing in Qazvin, Iran in 2020. The findings showed that the prevalence of falls was rather high. The results also indicated that increasing age, the number of physical illnesses and medication used, balance impairment, and physical inactivity increased the risk of falls among older people.

\section{Introduction}

enility is a worldwide phenomenon that continues to affect all regions of the globe [1]. Developing nations, like developed countries, are facing an aging population.

The demographic transition of birth and death rates has resulted in a strong modification in the age structure of Asian countries [2]. In Iran, the proportion of seniors 60 years and above raised from $7.2 \%$ in 2006 to $9.3 \%$ in 2011 , and is projected to grow to $10.5 \%$ in 2025 and $21.7 \%$ in 2050 [3]. The fast changes in the number of seniors make important concerns, markedly in connection with their health. Aging is associated with declining in both physiological and psychological functions that may cause a high level of dependency [4].

Balance ability is decreased by advancing age. Age-related balance impairments are well-documented. Many changes in physical and neurological systems in older age impair the ability to recognize any changes in the base of support as well as the center of mass for rapid reaction [5]. Balance impairments can lead to high fall risk and mobility decline in older adults. Falls are one of the most common problems and deadly accidents in older age. It is estimated that at least one out of every three people over age 65 falls annually. This rate comes to one out of two after the age of 80 years old [6].

Fall is the most common reason for injuries among the aged population. Fall-related injuries are problematic, costly, and can lead to severe health and economic issues [7]. One-quarter of falls among older people may lead to serious, perhaps deadly injuries, such as fractures, joint dislocation, and head trauma [8]. The tendency for fallrelated injuries is due to a high prevalence of medical problems and chronic conditions among older people [9].

Fall is a multifactorial condition caused by extrinsic and intrinsic risk factors. Extrinsic factors are mostly related to the environment, like reduced lighting, slippery ground, rough walkway surface, insufficient handrails as well as obstacles in the walking path [10]. However, only a small number of accidental falls are due to external factors, but more commonly by intrinsic factors, or a combination of intrinsic and extrinsic factors [11]. Intrinsic factors include leg muscle weakness, reduction in joint flexibility, gait and balance difficulties, cognitive problems, vestibular dysfunction, visual impairment, depression, and poly-medications [9, 12-16].

The world's aged population is growing fast; thus, the number of falls and its related medical care costs are increasing in the coming years. Although falls are common, dangerous, and costly in aged people, they can be prevented by decreasing the modifiable fall risk factors [17]. In Iran, many studies have investigated the incidence of falls and their correlated factors in communitydwelling older adults residing in Babol [9], Khoramabad [18], Bojnurd [19], Shiraz [20], and Mashhad [21], but only one research [9] examined the predictors of home fall and focused more on the external factors. Furthermore, various results have been reported regarding the role of demographic factors on falls among older adults. In some studies, age was found among the predictors of fall $[9,22]$; however, such associations have not been confirmed in other studies [23, 24]. Regarding gender, while some studies have suggested that females fell 
significantly more than men $[18,20]$, others have not reported that $[9,19]$. Furthermore, the results of some studies have shown a significant association between the level of education and the incidence of falls among older people $[22,23]$. However, others could not find this result $[19,25]$. Therefore, the purpose of this research was to ascertain the intrinsic factors of home fall among a sample of Iranian older adults.

\section{Materials and Methods}

This cross-sectional research was conducted on 300 seniors aged 60 years old and above residing in Qazvin City, Iran. Samples were chosen by cluster sampling technique from five regions of the city. One mosque and park were selected randomly out of every district and then, the eligible seniors were picked from these areas by the convenience sampling method. Inclusion criteria were the age of 60 years and above, ability to communicate verbally, and willingness to participate in the research. Participants who experienced psychiatric issues (e.g. Alzheimer's disease or other types of dementia), a physical impairment (e.g. wheelchair use), or terminal illness were excluded from the study. To determine the sample size, by considering the $35 \%$ prevalence of falls among older people $(\mathrm{P}=0.35)$ extracted from results of a similar study [9], and an alpha level of 0.05 , the total sample size was calculated to be 225 . By considering a $30 \%$ nonresponsive rate, 300 subjects were finalized for this study.

Demographic checklist, the Abbreviated Mental Test Score (AMTS), the Visual Analogue Scale (VAS), and Timed Up and Go (TUG) test were applied for collecting the data. A demographic checklist, assessed age, gender, marital status, levels of education, job, financial situation, living arrangement, smoking, history of physical or mental problems, use of assistive devices, and the number of prescribed medicines.

To ascertain the Body Mass Index (BMI), anthropometric characteristics, such as weight and height were precisely measured. BMI was calculated by dividing weight $(\mathrm{kg})$ by the square of height $\left(\mathrm{m}^{2}\right)$. The AMTS is a 10-item cognitive test for rapidly assessing elderly patients for the possibility of dementia. On this scale, a score of 6 or less indicates dementia. Bakhtiyari et al. reported that the Persian version of AMT had good discriminated validity in the diagnosis of cognitive impairment of institutionalized older adults. Additionally, the internal consistency (Cronbach'salpha coefficient $=0.76$ ) and the external reliability (Inter-Class Correlation coefficient $(\mathrm{ICC})=0.89$ ) of this instrument were in the acceptable ranges [26].
The physical activity level of older respondents was determined using Visual Analogue Scale (VAS), which is a standard and a graphic rating scale to quantify some soft variables, like pain, skill, activity, quality of teamwork, and confidence. VAS as a subjective measure of physical activity consists of a scaled frame from zero to $10 \mathrm{~cm}$. Values obtained from this tool can be analyzed as a categorized variable so that the $10 \mathrm{~cm}$ of the scale is divided into three sections, as follows: 1-3 as less active, 4-7 as moderately active, and 8-10 as very active [27].

The TUG test has been widely applied to assess the balance control of seniors who live in the community and institutions. It measures the time taken to stand up from a chair, walk three meters, turn back, and sit down on the chair [28]. The test has demonstrated inter-rater reliability $(\mathrm{ICC}=0.99)$ and intra-rater reliability $(\mathrm{ICC}=0.99)$ in a sample of elderly people [29]. The TUG test also had satisfactory construct validity, Cronbach's alpha (0.81), and time stability (0.98) in Iranian older adults [30].

\section{Statistical analysis}

Data analysis was done using the Statistical Package for Social Sciences, version 23.0 (SPSS Inc., Chicago, IL, USA). The grouping variables were defined by frequencies and percentages and quantitative variables were defined by the mean and Standard Deviation (SD). The predictors associated with falls were determined using the logistic regression model. The normality assumptions were verified by Skewness and Kurtosis. The significance level was considered at $\mathrm{P}<0.05$.

\section{Results}

The seniors who met the criteria for inclusion in the study were 300 older people with a Mean \pm SD age of $70.11 \pm 8.90$ years in the age range of $60-98$ years. More than half of the older participants were male $(n=159$, $53 \%)$. The majority of them were married $(n=205$, $68.3 \%$ ), undergraduate (123 persons, $41.0 \%$ ), housewives or retirees (236 persons, 82\%), and lived with spouses and children (205 persons, 3.68\%). About $64.0 \%$ of them $(n=198)$ used the assistive devices and $12.7 \%$ of them $(n=50)$ reported smoking.

The Mean \pm SD time of completing the TUG test was $22.70 \pm 13.50$ seconds ranging from 13.5 to $66.0 \mathrm{sec}-$ onds. The Mean \pm SD time to complete the TUG test in the older people with a history of falls was $28.00 \pm 15.35$ seconds and among those without a history of falls was $19.1 \pm 10.63$ seconds. 
Table 1. Results of physical activity engagement among older participants with or without fall based on the gender

\begin{tabular}{ccccccc}
\hline \multirow{2}{*}{$\begin{array}{c}\text { Physical } \\
\text { Activity }\end{array}$} & \multicolumn{2}{c}{ Without A History of Fall, No(\%) } & \multicolumn{3}{c}{ With A History of Fall, No (\%) } \\
\cline { 2 - 6 } & High & Middle & Low & High & Middle & Low \\
\hline Man & $36(30.3)$ & $70(58.8)$ & $13(10.9)$ & $10(25.0)$ & $18(45.0)$ & $21(52.5)$ \\
Woman & $12(14.8)$ & $51(63.0)$ & $18(22.2)$ & $0(0.0)$ & $24(40.0)$ & $36(60.0)$ \\
Total & $48(24.0)$ & $121(60.0)$ & $3(15.0)$ & $1(1.0)$ & $42(42.0)$ & $56(56.0)$ \\
\hline
\end{tabular}

Пranian Rehabilitation Journal

The Mean \pm SD and standard deviation of physical activity was $5.10 \pm 2.21$. The majority of them reported to have moderate physical activity $(54.3 \%, \mathrm{n}=163)$ and only a quarter of them $(25 \%, n=49)$ reported having high physical activity. The results of physical activity levels among older participants with or without a history of falls based on gender are depicted in Table 1.

In general, the studied variables predicted 42.5 to 60 percent of falls among older people. The findings of logistic regression analysis revealed that the number of medicines used $(\mathrm{OR}=5.31, \mathrm{CI}=1.44-19.49)$, history of the physical disease $(\mathrm{OR}=1.31, \mathrm{CI}=1.01-1.70)$, age $(\mathrm{OR}=1.09, \mathrm{CI}=1.03-1.15)$, balance control $(\mathrm{OR}=1.04$, $\mathrm{CI}=0.07-1.01)$, and physical activity $(\mathrm{OR}=0.72$, $\mathrm{CI}=0.57-0.92$ ) were statistically significant predictors for fall. Increasing the age, increasing the number of physical illnesses and the number of medications used, the time needed to complete the TUG test, and decreasing the rate of physical activity strongly increased the risk of falls among older people (Table 2).

\section{Discussion}

In the present study, the prevalence of falls in Iranian older adults was $33.3 \%$. The prevalence of falls varies across the world. For instance, the results of the previous studies found that $50.8 \%$ of older adults in the United Arab Emirates [16] and $42.4 \%$ in the UK [31] fell each year. In Iran, the prevalence of falls among older adults ranged from $24.8 \%$ in Khoramabad [18] to $35.1 \%$ in Babol [9]. These variations might be due to the characteristics of the seniors under research, culture, and environmental factors.

The findings of the current research are in conformance with those from earlier studies $[9,14,16]$ indicating age as a predictor of falls among seniors. One-third of seniors aged 65 years and above fall at least one time in a year and this ratio reach $50 \%$ for cases over 85 years [10]. Likewise, Jafarian et al. [9] reported that the rate of falls among those aged 75 years old and above was 2.5 times more than younger counterparts. Increased risk of falls by advancing age may be due to physical and mental disorders, visual impairment, balance deficit, and use of multiple medications [32]. One of the most prominent impacts of age is the involuntary reduction of muscle mass and strength. Muscle mass declines about 3-8\% each decade after the age of 30 and this rate accelerates after the age of 60 . Such changes in leg muscle reduce the balance control and increase the exposure of falls in older people [17].

In the present study, inadequate physical activity was known as a risk factor for falling among the elderly. Several studies [33, 34] have reported the relationship between fall risk and level of physical activity among older adults in different countries. Inactivity seems to be related to an increased risk of falling through frailty and muscle weakness, a reduction in joint flexibility, bone density, cardiopulmonary endurance, coordination between limbs, reaction time, and balance control $[35,36]$.

In the current study, the history of chronic illnesses was a predictor of falls as elderly adults with a medical history of chronic conditions were more exposed to falls. Likewise, Jafarian et al. [9] reported that the rate of fall incidence among seniors with a history of chronic disease was 4.5 times higher than others. Also, Salarvand et al. [18] found a significant relationship between a history of chronic illnesses and fall occurrence. The prevalence of multiple chronic conditions increases by advancing age. Many chronic diseases might accelerate muscle mass and strength decline. For example, musculoskeletal conditions (rheumatoid arthritis, osteoporosis) decrease joint range of motion and sensory-depth activity and then, reduce balance control leading to an increase in the risk of falling [34]. Furthermore, neurological conditions, such as Parkinson's disease, multiple sclerosis, or strokes cause balance disturbance [37]. Chronic diseases cause older people to become weaker and this increases their chances of falling. Previous studies have found the 
Table 2. Results of internal factors predicting fall using the nonlinear regression model

\begin{tabular}{|c|c|c|c|c|c|c|}
\hline \multicolumn{2}{|c|}{ Variables } & B & $e^{\beta}(O R)$ & Sig. & Wald & OR \\
\hline \multicolumn{2}{|c|}{ Age } & 0.09 & 1.09 & 0.002 & 9.77 & $1.03-1.15$ \\
\hline Gender (Female) & Male & 0.32 & 1.378 & 0.707 & 0.14 & $0.26-7.33$ \\
\hline $\begin{array}{c}\text { Marital } \\
\text { Status (Single) }\end{array}$ & Married & $0.71-$ & 0.491 & 0.400 & 0.71 & $0.09-2.57$ \\
\hline \multirow{2}{*}{$\begin{array}{l}\text { Educational level (Di- } \\
\text { ploma and higher) }\end{array}$} & Illiterate & $0.28-$ & 0.757 & 0.559 & 0.34 & $0.30-1.92$ \\
\hline & High school & 0.56 & 1.744 & 0.355 & 0.86 & $0.54-5.66$ \\
\hline \multirow{2}{*}{ Job (Housewife) } & Retired & 0.60 & 1.827 & 0.333 & 0.94 & $0.54-6.19$ \\
\hline & Employed & 0.43 & 1.531 & 0.641 & 0.22 & $0.26-9.17$ \\
\hline \multirow{3}{*}{$\begin{array}{l}\text { Financial status } \\
\text { (Middle) }\end{array}$} & Very good & 0.25 & 1.283 & 0.742 & 0.11 & $0.29-5.68$ \\
\hline & Good & 0.55 & 1.740 & 0.502 & 0.45 & $0.35-8.76$ \\
\hline & Bad & 0.20 & 1.222 & 0.797 & 0.07 & $0.27-5.61$ \\
\hline \multirow{3}{*}{$\begin{array}{l}\text { Living arrangement } \\
\text { (with spouse) }\end{array}$} & With spouse & - & - & - & - & - \\
\hline & Alone & $0.42-$ & 0.659 & 0.639 & 0.22 & $0.12-3.76$ \\
\hline & $\begin{array}{l}\text { With spouse } \\
\text { and children }\end{array}$ & 0.08 & 1.081 & 0.899 & 0.01 & $0.32-3.61$ \\
\hline Smoking & Yes & -0.29 & 0.75 & 0.629 & 0.23 & $0.23-2.43$ \\
\hline $\begin{array}{l}\text { History of mental } \\
\text { illness }\end{array}$ & Yes & -0.31 & 0.736 & 0.454 & 0.57 & $0.33-1.64$ \\
\hline $\begin{array}{l}\text { History of physical } \\
\text { diseases }\end{array}$ & Yes & 0.27 & 1.312 & 0.041 & 4.18 & $1.01-1.70$ \\
\hline Assistive devices & Yes & 0.01 & 1.007 & 0.989 & 0.000 & $0.41-2.49$ \\
\hline \multirow{3}{*}{$\begin{array}{l}\text { Number of medicines } \\
\text { (0) }\end{array}$} & $1-2$ & 0.17 & 1.185 & 0.812 & 0.06 & $0.29-4.81$ \\
\hline & $3-4$ & 1.67 & 5.305 & 0.012 & 6.31 & $1.44-19.49$ \\
\hline & $>4$ & 1.20 & 3.311 & 0.108 & 2.58 & $0.77-14.27$ \\
\hline \multicolumn{2}{|c|}{ Timed Up and Go Test } & 0.04 & 1.039 & 0.011 & 6.48 & $0.07-1.01$ \\
\hline \multicolumn{2}{|c|}{ AMT } & -0.01 & 0.991 & 0.952 & 0.004 & $0.75-1.32$ \\
\hline \multicolumn{2}{|c|}{ Physical activity } & -0.32 & 0.724 & 0.007 & 7.26 & $0.57-0.92$ \\
\hline \multicolumn{2}{|c|}{ Body Mass Index (BMI) } & -0.03 & 0.973 & 0.814 & 0.05 & $0.77-1.23$ \\
\hline
\end{tabular}

OR: Confidence interval for OR; $\mathrm{e}^{\beta}(\mathrm{OR})$ : the chance B: Regression coefficient; B: Regression coefficient; AMT: Abbreviated Mental Test.

co-occurrence of diseases and multi-morbidity patterns among older adults [35].

According to the findings of the current research, the balance status measured by the TUG test was the predictor of falling. The TUG test is one of the most useful, inexpensive, and economical ways to assess balance in older people. In this test, a higher score indicates less balance control; therefore, a greater chance of falling.
Morris et al. [28] also showed that balance status with the TUG test is a strong predictor of falls in older women with a history of vertebral fracture. Kristensen et al. also reported that the probability of fall in the older people who were not able to complete the TUG test was three times higher than others [38]. Generally, balance and coordination problems increase the exposure for falls among older adults. One out of two falls happens dur- 
ing performing the tasks, which require proper static and dynamic balance [39].

In the present study, the number of medications used was identified as another predictor of falls in older people. The majority of the older adults use cardiac, hypertensive, sedative, and diuretic medications. Most of these medications cause older people to experience falls due to their side effects, including dizziness, imbalance, and drowsiness. Nabavi et al. also found a significant relationship between sedative use and reports of falling down among a sample of Iranian older adults [19]. Furthermore, older people who take diuretics need to wake up at night in order to urinate that increases the risk of incidental falls.

\section{Conclusion}

The present study identified a high prevalence of falling among Iranian older adults residing in Qazvin City, Iran in 2018. The results indicated that advanced age, the number of physical illnesses and medicines used, poor balance, and insufficient physical activity were internal predictors of fall among older people. Hence, changes in lifestyle, such as engaging in regular physical activity and balance training, adjusting the medications used, and self-management of the health condition can effectively reduce the risk of falls in older adults.

\section{Limitations}

The sample of this study was community-dwelling elderly adults; thus, it may be hard to generalize the findings to the institutionalized elderly. Another limitation of the research is that only the seniors in the public locations were assessed, and those who were not able to be in these places were not included in this study.

\section{Suggestions for future studies}

It is suggested to conduct studies in the future to investigate the predictors of falls in institutionalized older adults. Additionally, future studies should assess the role of home safety in the prevention of home falls among older adults.

\section{Ethical Considerations}

\section{Compliance with ethical guidelines}

The study was confirmed by the Ethics Committee of Qazvin University of Medical Sciences, Qazvin, Iran (IR.QUMS.REC.1396.343). The samples were informed about the aims, procedures, promising profits, and disadvantages of the research. Additionally, attendants were informed that their contribution was voluntary and they were ensured that the obtained information will be kept confidential. The written informed consent was signed by all the participants and this research was directed in accordance with the Declaration of Helsinki.

\section{Funding}

The current paper was extracted from MSc thesis of the first author, Department of Nursing, Faculty of Nursing and Midwifery, Qazvin University of Medical Sciences.

\section{Authors' contributions}

Conceptualization, Investigation, and Writing - original draft: Amaneh Bagheri Roochi, Fatemeh Mohammadi, Hossein Khorani, Seyedeh Ameneh Motalebi; Data collection: Amaneh Bagheri Roochi; Methodology and Writing - review \& editing: Fatemeh Mohammadi, Hossein Khorani, Seyedeh Ameneh Motalebi; Data analysis: Seyedeh Ameneh Motalebi; Supervision: Seyedeh Ameneh Motalebi.

\section{Conflict of interest}

The authors confirmed no conflict of interests.

\section{Acknowledgments}

The authors would like to thank all older participants who contributed to this research.

\section{References}

[1] Thomas E, Battaglia G, Patti A, Brusa J, Leonardi V, Palma A et al. Physical activity programs for balance and fall prevention in elderly: A systematic review. Medicine. 2019; 98(27):e16218-e. [DOI:10.1097/MD.0000000000016218] [PMID] [PMCID]

[2] Pahlevanian AA, Najarian R, Adabi S, Mirshoj MS. The prevalence of fall and related factors in Iranian elderly: A systematic review. Archives of Rehabilitation. 2020; 21(3):286303. [DOI:10.32598/RJ.21.3.2084.6]

[3] Rashedi V, Iranpour A, Mohseni M, Borhaninejad V. Risk factors for fall in elderly with diabetes mellitus type 2. Diabetes \& Metabolic Syndrome. 2019; 13(4):2347-51. [PMID]

[4] Iranagh JA, Motalebi SA, Mohammadi F. A theoretically based behavioral nutrition intervention for elderly women: A cluster randomized controlled trial. International Journal of Gerontology. 2018; 12(2):127-32, [DOI:10.1016/j. ijge.2017.08.007]

[5] Osoba MY, Rao AK, Agrawal SK, Lalwani AK. Balance and gait in the elderly: A contemporary review. Laryngoscope In- 
vestigative Otolaryngology. 2019; 4(1):143-53. [DOI:10.1002/ lio2.252] [PMID] [PMCID]

[6] Gürler H, Bayraktar N. The effectiveness of a recurrent fall prevention program applied to elderly people undergoing fracture treatment. International Journal of Orthopaedic and Trauma Nursing. 2021; 40:100820. [DOI:10.1016/j. ijotn.2020.100820] [PMID]

[7] Zhang S, Xu W, Zhu Y, Tian E, Kong W. Impaired multisensory integration predisposes the elderly people to fall: A systematic review. Frontiers in Neuroscience. 2020; 14:411. [DOI:10.3389/fnins.2020.00411] [PMID] [PMCID]

[8] Kalula SZ, Ferreira M, Swingler GH, Badri M. Risk factors for falls in older adults in a South African urban community. BMC Geriatrics. 2016; 16:51. [DOI:10.1186/s12877-016-0212-7] [PMID] [PMCID]

[9] Jafarian Amiri S, Zabihi A, Aziznejad Roshan P, Hosseini S, Bijani A. [Fall at home and its related factors among the elderly in Babol City Iran (Persian)]. Journal of Babol University of Medical Sciences. 2013; 15(5):95-101. http://jbums.org/ article-1-4527-en.html

[10] Rowe RJ. Fall prevention: Core characteristics and practical interventions. Home Health Care Management \& Practice. 2011; 23(1):20-6. [DOI:10.1177/1084822309360382]

[11] Rubenstein LZ. Falls in older people: Epidemiology, risk factors and strategies for prevention. Age and Ageing. 2006; 35(suppl 2):ii37-41. [DOI:10.1093/ageing/afl084] [PMID]

[12] Dai W, Tham YC, Chee ML, Tan NYQ, Wong KH, Majithia $\mathrm{S}$, et al. Falls and recurrent falls among adults in a multi-ethnic Asian population: The Singapore epidemiology of eye diseases study. Scientific Reports. 2018; 8(1):7575. [DOI:10.1038/ s41598-018-25894-8] [PMID] [PMCID]

[13] Ahmad Kiadaliri A, Turkiewicz A, Englund M. Educational inequalities in falls mortality among older adults: Population-based multiple cause of death data from Sweden. Journal of Epidemiology and Community Health. 2018; 72(1):68-70. [DOI:10.1136/jech-2017-209616] [PMID]

[14] Yu PL, Qin ZH, Shi J, Zhang J, Xin MZ, Wu ZL, et al. Prevalence and related factors of falls among the elderly in an urban community of Beijing. Biomedical and Environmental Sciences. 2009; 22(3):179-87. [DOI:10.1016/S0895-3988(09)60043-X]

[15] Ryu E, Juhn YJ, Wheeler PH, Hathcock MA, Wi CI, Olson JE, et al. Individual housing-based socioeconomic status predicts risk of accidental falls among adults. Annals of Epidemiology. 2017; 27(7):415-20. e2. [DOI:10.1016/j.annepidem.2017.05.019] [PMID]

[16] Sharif SI, Al-Harbi AB, Al-Shihabi AM, Al-Daour DS, Sharif RS. Falls in the elderly: Assessment of prevalence and risk factors. Pharmacy Practice. 2018; 16(3):1206. [DOI:10.18549/ PharmPract.2018.03.1206] [PMID] [PMCID]

[17] Motalebi SA, Loke SC. Efficacy of progressive resistance tube training in community dwelling older adults: A pilot study. International Journal of Gerontology. 2014; 8(4):213-8. [DOI:10.1016/j.ijge.2013.12.007]

[18] Salarvand S, Birjandi M, Shamshiri M. [Assessing prevalence of fallings and their relation with chronic conditions for older people living in Khoramabad, Iran (Persian)]. The Horizon of Medical Sciences. 2008; 13(4):59-65. http://hms.gmu. ac.ir/article-1-301-en.html
[19] Nabavi SH, Hatami ST, Norouzi F, Gerivani Z, Hatami SE Monadi Ziarat $\mathrm{H}$, et al. [Prevalence of fall and its related factors among older people in Bojnurd in 2015 (Persian)]. Iranian Journal of Ageing. 2016; 11(3):466-73. [DOI:10.21859/sija1103466]

[20] Ghanbary A, Salehi Dehno N, Moslemi Haghighi F, Torabi $\mathrm{M}$. [The prevalence and correlates of falling down in the older adults over 55 years in Shiraz (Persian)]. Iranian Journal of Ageing. 2013; 8(1):64-70. http://salmandj.uswr.ac.ir/article1-548-en.html

[21] Vakili V, Taghipour A, Mosa Farkhani E, Bahrami HR, beygi B, Pirizadeh E. Risk factors for falls among elderly people: A population-based case-control study. Elderly Health Journal. 2019; 5(2):84-91. [DOI:10.18502/ehj.v5i2.2154]

[22] Marashi T, Ghadiri S, Ramezankhani A, Khodkarim S [Study of fall and some of its related individual factors among the elderly attending to health centers affiliated to health network of Rey city in 2017 (Persian)]. Journal of Health in the Field. 2018; 6(2):49-57. [DOI:10.22037/jhf.v6i2.21942.]

[23] Davoodi F, Etemad K, Tanjani P, Khodakarim S. [The relationship between depression and cognitive impairment with falls leading to fractures in elderly (Persian)]. Journal of Safety Promotion and Injury Prevention. 2017; 4(2):75-82. https:// journals.sbmu.ac.ir/spip/article/view/14129

[24] Tanjani PT, Akbarpour S, Ainy E, Soori H. Socio-demographic risk factors of mobility dysfunction and limitations in physical functioning disability among the elderly in Iran: A nationwide cross-sectional survey. Journal of the Pakistan Medical Association. 2015; 65(10):1060-4. [PMID]

[25] Salavati M, Baharlouei H, Akhbari B. [The relationship between fear of falling and level of education and living style in the elderly (Persian)]. Journal of Research in Rehabilitation Sciences. 2015; 11(4):257-62. http:/ /jrrs.mui.ac.ir/index.php/ jrrs/article/view/ 2064

[26] Bakhtiyari F, Foroughan M, Fakhrzadeh H, Nazari N, Najafi B, Alizadeh M, et al. [Validation of the Persian version of Abbreviated Mental Test (AMT) in elderly residents of Kahrizak charity foundation (Persian)]. Iranian Journal of Diabetes and Metabolism. 2014; 13(6):487-94. http://ijdld.tums.ac.ir/ article-1-5271-en.html

[27] Morgan RO, Devito CA, Stevens JA, Branche CM, Virnig $\mathrm{BA}$, Wingo PA, et al. A self-assessment tool was reliable in identifying hazards in the homes of elders. Journal of Clinical Epidemiology. 2005; 58(12):1252-9. [DOI:10.1016/j.jclinepi.2005.04.001] [PMID]

[28] Morris R, Harwood RH, Baker R, Sahota O, Armstrong S, Masud T. A comparison of different balance tests in the prediction of falls in older women with vertebral fractures: $\mathrm{A} \mathrm{CO}-$ hort study. Age and Ageing. 2007; 36(1):78-83. [DOI:10.1093/ ageing/afl147] [PMID]

[29] Shumway-Cook A, Brauer S, Woollacott M. Predicting the probability for falls in community-dwelling older adults using the Timed Up \& Go Test. Physical Therapy. 2000 80(9):896-903. [DOI:10.1093/ptj/80.9.896] [PMID]

[30] Aslankhani MA, Farsi A, Fathirezaie Z, Zamani Sani SH Aghdasi MT. [Validity and reliability of the timed up and go and the anterior functional reach tests in evaluating fall risk in the elderly (Persian)]. Iranian Journal of Ageing. 2015 10(1):16-25. http:/ / salmandj.uswr.ac.ir/article-1-720-en.html 
[31] Downton JH, Andrews K. Prevalence, characteristics and factors associated with falls among the elderly living at home. Aging. 1991; 3(3):219-28. [DOI:10.1007/BF03324009] [PMID]

[32] Swanenburg J, de Bruin ED, Uebelhart D, Mulder T. Falls prediction in elderly people: A 1-year prospective study. Gait \& Posture. 2010; 31(3):317-21. [DOI:10.1016/j.gaitpost.2009.11.013] [PMID]

[33] Plouvier S, Gourmelen J, Chastang JF, Lanoë JL, Leclerc A. Low back pain around retirement age and physical occupational exposure during working life. BMC Public Health. 2011; 11:268. [DOI:10.1186/1471-2458-11-268] [PMID] [PMCID]

[34] Taghipour M, Hosseini SR, Pouraria S. [The relationship between physical activity and balance control in the elderly (Persian)]. Iranian Journal of Ageing. 2016; 10(4):60-7. http:// salmandj.uswr.ac.ir/article-1-800-en.html

[35] Immonen M, Haapea M, Similä H, Enwald H, Keränen $\mathrm{N}$, Kangas M, et al. Association between chronic diseases and falls among a sample of older people in Finland. BMC Geriatrics. 2020; 20(1):225. [DOI:10.1186/s12877-020-01621-9] [PMID] [PMCID]

[36] McPhee JS, French DP, Jackson D, Nazroo J, Pendleton N, Degens H. Physical activity in older age: Perspectives for healthy ageing and frailty. Biogerontology. 2016; 17(3):567-80 [DOI:10.1007/s10522-016-9641-0] [PMID] [PMCID]

[37] Alpert PT. Postural balance: Understanding this complex mechanism. Home Health Care Management \& Practice. 2013; 25(6):279-81. [DOI:10.1177/1084822313496790]

[38] Kristensen MT, Foss NB, Kehlet H. Timed "up \& go" test as a predictor of falls within 6 months after hip fracture surgery. Physical Therapy. 2007; 87(1):24-30. [DOI:10.2522/ ptj.20050271] [PMID]

[39] Toraman A, Yıldırım NÜ. The falling risk and physical fitness in older people. Archives of Gerontology and Geriatrics. 2010; 51(2):222-6. [DOI:10.1016/j.archger.2009.10.012] [PMID] 